\title{
Influence of management on equine digestion
}

\author{
Sarah Ralston, VMD, PhD, DACVN
}

SEBS, Rutgers University

New Brunswick, NJ, USA

\section{Introduction}

The management schemes for horses can directly influence their ability to digest and absorb nutrients from their feeds. Amounts fed and times that the meals are offered can alter digestion and utilization of a variety of nutrients as can the types and forms of feeds offered. Exercise will also directly impact feed digestion/utilization. This presentation will review what is known to date and offer some practical recommendations for maximization of digestive efficiency.

\section{Feed types and processing}

The types and physical form of feeds differ with respect to their digestibility. Starches and sugars in processed (flaked, rolled, steamed or popped) grains are more rapidly and efficiently digested than in whole, unprocessed grains (Hoekstra et al, 1999; Julliand et al., 2006, NRC, 2007, Keinzle et al 1997) though the overall benefits may be negligible to the actual biology of the horse, conferring only a $10 \%$ increase or less in most cases. Oat starch is more digestible than corn starch (Kienzle et al, 1997, NRC, 2007) which may account for the general perception that oats are safer than corn to feed in large amounts. If fed in large amounts to horses unaccustomed to the feed, cornstarch will be more likely to bypass digestion and absorption than oat starch, and be delivered in large amounts to the cecum and large colon where the resultant disruption of normal fermentation can result in altered digestion and even colic and laminitis (DeFombelle et al, 2004, Julliand et al, 2001; Medina at al, 2002; Meyer et al, 1993; Moore and Dehority, 1993). Large meals also result in more rapid emptying rates than small meals and high starch feeds are more rapidly delivered to the small intestine than are low starch feeds (Metayer et al, 2006). To maximize digestion and absorption in the small intestine it is best to feed relatively small amounts per meal and avoid feeds with high concentrations of sugars and starches.

Grass hays tend to accumulate sugar/fructan over the course of the day light hours and can be quite high in the highly fermentable non-structural carbohydrates (Longland et al, 2006), especially during environmental stresses such as drought or over night frosts. Horses that are insulin resistant and prone to laminitis appear to be more sensitive to the higher fructan forages, whether the insulin resistance is caused by pituitary dysfunction, obesity or genetic predisposition (Harris et al, 2006; Kronfeld et al, 2005; Treiber et al, 2006). It is recommended that horses prone to laminitis be offered access to pasture only in the morning hours and that they be kept off pasture completely after overnight freezing temperatures and during droughts.

Horses adapted to high grain rations are more efficient at digesting and absorbing the starches (Hintz and Argenzio, 1971). However they will be relatively insulin resistant (higher insulin secretion per unit of glucose) relative to those fed restricted starch/sugar $(<30 \%)$ and higher high fat $(6-12 \%)$ and fiber $(>12 \%)$ rations (Kronfeld et al, 2005; Pagan et al, 2002). However there is no evidence that feeding high amounts of fat alone will improve insulin sensitivity or that, unlike other species, high fat rations reduce gastric emptying rate (Lorenzo-Figueras et al, 2005). Supplementation of moderate amounts of fat $(7 \%$ in total ration) may enhance digestion in the large intestine (Bush et al, 2001) but large amounts of fat added to the large intestine actually suppresses fermentation and 
should be avoided (Jansen et al, 2002, NRC, 2007). It takes up to 2 months for horses to adapt metabolically to rations containing $>7 \%$ fat (NRC, 2007).

\section{Feeding times and amounts}

Equine animals were adapted over evolutionary time to consume primarily forages, though in summer months the grasses also have "seed heads" that are high starch grains. If adapted to free access to forages or concentrates horses and ponies usually consume relatively small meals $(<0.5 \% \mathrm{BW})$ at no more than 3 hour intervals throughout a 24 hour period, rarely voluntarily going for more than 3 to 4 hours with out eating. (Ralston and Baile, 1983; Ralston, 1984, NRC, 2007). When first introduced to a ration, especially if it consists of highly palatable feeds, ponies especially will tend to eat in excess of their needs if offered free access, increasing the risk of colic (Cohen, 1997, Treiber et al, 2006, NRC, 2007) and laminitis (Treiber et al, 2006, Harris et al, 2006; NRC, 2007) and resulting in excessive weight gain if the access is prolonged over a period of weeks to months (NRC, 2007). However body weights and intakes will eventually stabilize (Ralston and Baile, 1983; Ralston, 1984; NRC, 2007), though usually at a higher amount of body fat than is desirable for athletic performance. If free access to feeds is not a viable option for an athletic horse, offering a ration that consists predominantly of forage in relatively small amounts at frequent intervals best mimics the natural pattern of foraging.

Meals of concentrates that contain starch in excess of $0.2-0.4 \% \mathrm{BW}$ reduce the overall digestibility of the feed ( deFombelle et al., 2004, NRC, 2007) due to the fact that the starch bypasses the more efficient small intestinal enzymatic digestion (Kienzle et al, 1994; deFombelle et al, 2003, 2004), and is passed on to the cecum and large colon where fermentative digestion is less efficient (Ibid). Large excess of highly fermentable materials in the cecum/large colons will alter efficiency of digestion of other nutrients, and adversely affect volatile fatty acid formation and availability (deFombelle et al, 2003; 2004, Goodson et al, 1988, NRC, 2007).

Horses have significantly higher insulin responses to glucose or starch challenges in the morning hours than in the afternoon/early evening if not stressed
(Ralston, 2002, 2004; Gordon and McKeever, 2005). It is thought that the apparent shifts in insulin sensitivity may be related to the normal diurnal variation in plasma cortisol since increased plasma cortisol due to stress or pituitary dysfunction is well documented to induce relative insulin resistance (Ralston, 2004). High starch feeds offered in the afternoon/early evening therefore will theoretically be converted more efficiently into energy/fat storage than those offered in the early morning hours. Since forages accumulate sugars/starches during the day via photosynthesis that are converted over night to cellulose or other structural fibers, it appears the horse's endogenous rhythm of insulin mimics the cycle of sugar/starch accumulation in forages (Longland and Byrd, 2006). Disruption of that cycle by feeding large amounts of high starch feeds has been repeatedly associated with decreased insulin sensitivity in a variety of horses and ponies (Harris et al, 2006, Ralston, 2004; Treiber et al, 2006) and an increased risk of colic (Cohen, 1997).

Gastric ulceration is very common in performance horses of all types (Begg and O'Sullivan, 2003; Jonsson et al, 2006, McClure et al, 2005Roy et al, 2005). Prolonged fasting ( $>12$ hours, NRC, 2007), confinement to stalls as opposed to being out in pasture, (Murray et al, 1996; NRC, 2007 ), strenuous exercise (Lorenzo-Figueras and Merrit, 2002, Murray et al, 1996) and high grain rations (Murray et al, 1996) have all been incriminated as contributing factors. Feeding alfalfa hay as opposed to grass hays has been reported to apparently reduce the incidence, possibly due to the buffering effects of the higher protein and calcium (Nadeau et al, 2000, 2003a,b). The addition of edible oils per se does not reduce the incidence of gastric ulceration (Frank et al, 2005). However if the amount of high starch concentrates needed to maintain condition can be reduced by feeding the more calorically dense high fat (7-12\%) feeds it may help reduce the incidence and severity of ulceration. Ideally the best management to reduce gastric ulceration is to provide performance horses with free access to pasture and/or legume hay, avoid prolonged fasts and not restrict hay prior to asking for extreme physical effort.

\section{Exercise}

Mild to moderate exercise increases passage rates in horses (Lindberg et al, 2006, Pagan et al, 1998), resulting in slightly reduced rates of digestibility, 
especially of forages. However aerobic training increases insulin sensitivity and enhances digestion of starches and fat in the small intestine (Ralston, 2004, NRC, 2007). Intense exercise will reduce feed intake for up to 24 hours after the episode, even though this is the period when digestive and metabolic efficiency in restoring glycogen/fat stores is maximal (Gordon et al, 2006; NRC, 2007). It is best to feed relatively small amounts of calorically dense feeds at frequent intervals after intense effort to restore body fat/glycogen most efficiently.

\section{References}

Begg, L.M.; O'Sullivan, C.B. The prevalence and distribution of gastric ulceration in 345 racehorses. Australian Vet. J. 81:199-201, 2003.

Bush, J.; Freeman, D.; Kline, K.; Merchen, N. Fahey, G.J. Dietary fat upplementation effects on in vitro nutrient disappearance and in vivo nutrient intake and total tract digestibility by horses. J. Anim. Sci. 79, 232-239, (2001).

Cohen, N.D. Epidemiology of colic. Vet. Clinics NA: Eq. Prac.13: 191-201, 1997.

de Fombelle, A.; Varloud, M.; Goachet, A.G.; Jacotot, E.; Philippeau, C.; Drogoul, C.; Julliand, V. Characterisation of the microbial and biochemical profile of the different segments of the digestive tract in horses fed two distinct diets. Anim Sci. 77: 293-304, 2003.

de Fombelle, A.; Veiga, L.; Drogoul, C.; Julliand, V. Effect of diet composition and feeding pattern on the prececal digestibility of starches from diverse botanical origins measured with the mobile nylon bag technique in horses. J. Anim. Sci. 82, 3625-3634, 2004.

Frank, N., Andrews, F., Elliot, S.; Lew, J. Effect of dietary oils on the development of gastric ulcers in mares. Am. J. Vet. Res. 66, 2006-2011, 2003.

Goodson, J., Tyznik, W.J., Cline, J.H. and Dehority, B.A. Effects of an abrupt diet change from hay to concentrate on microbial numbers and physical environment in the cecum of the pony. Appl. Environ. Microbiol, 54, 1946-1950, 1988.

Gordon, M.E.; McKeever, K.H. Diurnal variation of ghrelin, leptin, and adiponectin in Standardbred mares. Journal of Animal Science. 83(10):2365-71, 2005.

Gordon, M.E.; McKeever, K.H.; Bokman, S.; Betros, C.L.; Manso-Filho, H.; Liburt, N.; Streltsova, J. Interval exercise alters feed intake as well as leptin and ghrelin concentrations in Standardbred mares. Eq. Vet. J. (Suppl). 36:596-605, 2006.

Harris, P.; Bailey, S.; Elliot, J.; Longland, A. Counter measures for pasture associated laminitis in ponies and horses. J. Nutr.136. 2114S-2121S, 2006.

Hintz, H.F.; Argenzio, R.A.; Schryver, H.F. Digestion coefficients, blood glucose levels and molar percentage of volatile acids in intestinal fluid of ponies fed varying foragegrain ratios. J. Anim. Sci. 33, 992-995, 1971.

Hoekstra, K.E.; Newman, K.; Kennedy, M.A.P.;Pagan, J.D. Effect of corn processing on glycemic response in horses. In: Equine Nutrition and Physiology Symposium, Ed: ENPS, Raleigh, North Carolina. pp 144-148, 1999.
Jansen, W., Geelen, S., Van der Kuilen, J. and Beynen, A. Dietary soyabean oil depresses the apparent digestibility of fibre in trotters when substituted for an iso-energetic amount of corn tarch or glucose. Eq. Vet. J. 34: 302-305, 2002.

Jonsson H.; Egenvall A. Prevalence of gastric ulceration in Swedish Standardbreds in race training. Equine Veterinary Journal. 38(3):209-13, 2006.

Julliand, V.; de Fombelle, A.; Drogoul, C.; Jacotot, E. Feeding and microbial disorders in horses: 3-Effects of three hay:grain ratios on microbial profile and activities. Journal of Equine Veterinary Science 21, 543-546, 2001.

Julliand, V.; De Fombelle, A.; Varloud, M. Starch digestion in horses: the impact of feed processing. Livestock science Elsevier, 2006, pp 1-9.

Kienzle, E.; Pohlenz, J.; Radicke, S. Morphology of starch digestion in the horse. J. Vet. Med. 44, 207-221, 1997.

Kronfeld, D.S.; Treiber, K.; Hess, T.M.; Boston, R.C. Insulin resistance in the horse:

Definition, detection, and dietetics. J. Anim. Sci. 83(E. Suppl.):E22-E31, 2005.

Lindberg, J.E;. Essen-Gustavsson B.; Dahlborn, K.; GottliebVedi, M.; Jansson A.

Exercise response, metabolism at rest and digestibility in athletic horses fed high-fat oats. Equine Veterinary Journal. Supplement. (36):626-30, 2006.

Longland AC. Byrd BM. Pasture nonstructural carbohydrates and equine laminitis. $\mathrm{J}$.

Nutr. 136(7 Suppl):2099S-2102S, 2006.

Lorenzo-Figueras, M.; Merritt AM. Effects of exercise on gastric volume and $\mathrm{pH}$ in the proximal portion of the stomach of horses. Am. J. Vet. Res. 63(11):1481-7, 2002.

Lorenzo-Figueras, M.; Preston, T.; Ott, E.A.; Merritt, AM. Mealinduced gastric

relaxation and emptying in horses after ingestion of high-fat versus high-carbohydrate diets. Am. J. Vet. Res. 66:897-906, 2005.

McClure, S.R.; Carithers, D.S.; Gross, S.J.; Murray, M.J. Gastric ulcer development in

horses in a simulated show or training environment. J. Am. Vet. Med. Assoc. 227(5):775-7, 2005.

Medina, M.; Girard, I.D.; Jacotot, E.; Julliand, V. Effect of a preparation of Saccharomyces cerevisiae on microbial profiles and fermentation patterns in the large intestine of horses fed a high fiber or a high starch diet. J. Anim. Sci. 80, 2600-2609, 2002.

Metayer, N.; Lhôte, M.; Bahr, A.; Cohen, N.D.; Kim, I., Roussel, A.J.; Julliand, V. Meal size and starch content affect gastric emptying in horses. Eq. Vet. J. 36: 436-440, 2004.

Meyer, H.; Radicke, S.; Kienzle, E.; Wilke, S.; Kleffken, D.; Illenseer, M. Investigations on preileal digestion of oats, corn, and barley starch in relation to grain processing. Proc 13th Eq. Nutr. Physiol.Soc, Gainsville, Florida. 1993, pp 9297.

Moore, B.E.; Dehority, B.A. . Effects of diet and hindgut defaunation on diet digestibility and microbial concentrations in the cecum and colon of the horse. J. Anim. Sci. 71: 33503358, 1993.

Murray, M.J.; Schusser, G.F.; Pipers, F.S.; Gross, S.J. ;Factors associated with gastric lesions en thoroughbred racehorses. Eq. Vet. J. 28: 368-374, 1996.

Nadeau, J.A.; Andrews, F.M.; Mathew, A.G.; Argenzio, R.A.; Blackford, J.T; Sohtell, M.; Saxton, A.M. Evaluation of diet as a cause of gastric ulcers in horses. American Journal of Veterinary Research 61, 784-790, 2000. 
Nadeau, J.A.; Andrews, F.M.; Patton, C.S.; Argenzio, R.A.; Mathew, A.G.; Saxton, A.M. Effects of hydrochloric, acetic, butyric, and propionic acids on pathogenesis of ulcers in the nonglandular portion of the stomach of horses. Am. J. Vet. Res. 64, 404-412, 2003a.

Nadeau, J.A., Andrews, F.M., Patton, C.S., Argenzio, R.A., Mathew, A.G. and Saxton, A.M. Effects of hydrochloric, valeric, and other volatile fatty acids on pathogenesis of ulcers in the nonglandular portion of the stomach of horses. Am. J. Vet. Res. 64, 413-417, 2003b.

Nationa Research Council (NRC). Nutrient requirements of Horses, 6th ed. National Academy Press, Washington, DC, 2007, 341pp.

Pagan, J.D.; Harris, P.; Brewster-Barnes, T.; Duren, S.E.; Jackson, S.G. Exercise affects digestibility and rate of passage of all-forage and mixed diets in thoroughbred horses. J. Nutr. 128(12 Suppl):2704S-2707S, 1998.

Pagan, J.; Geor, R.; Harris, P.; Hoekstra, K.;Gardner, S.;Hudson, C.; Prince, A. Effects of fat adaptation on glucose kinetics and substrate oxidation during low-intensity exercise. Equine Vet. J. suppl. 34, 33-38, 2002.

Ralston, S.L. Controls of feeding in horses. J. Anim. Sci. 59:1354-1361, 1984.
Ralston, SL. Insulin and Glucose Regulation. Vet. Clin. N. Am. Eq Prac. 18:295-304,

2002.

Ralston, SL. Hyperinsulinemia and glucose intolerance. In: Equine Internal Medicine, 2nd

Edition. Reed, S, Bayly W, Sellon D. (eds), Elsevier, St. Louis, MO. pp.1599-1603, 2004.

Ralston, S.L. Evidence Based Equine Nutrition. Vet Clin. N. Am. Eq. Prac. 23:365-384, 2007.

Ralston, S.L., Baile, C.A. Review of factors controlling feed intake in ponies. Neurosci. Biobehav. Rev. 7:465-470,1983.

Ralston, S.; Sullins, K.; Stashak, T. Digestion in horses after resection or ischemic insult of the large colon. Am. J. Vet. Res. 47: 2290-2293, 1986.

Roy, M.A.; Vrins, A.; Beauchamp, G.; Doucet, M.Y. Prevalence of ulcers of the squamous gastric mucosa in standardbred horses. J. Vet. Int. Med. 19:744-50, 2005.

Treiber, K.; Kronfeld, D.; Hess, T.; Byrd, B.; Splan, R.; Staniar, $\mathrm{W}$. Evaluation of genetic and metabolic predispositions and nutritional risk factors for pasture-associated laminitis in ponies. J. Am. Vet. Med. Assoc. 228, 1538-1545, 2006. 